\title{
Modeling Strategies to Compute Natural Circulation Using CFD in a VHTR After a LOFA
}

\section{IMECE 2012}

Yu-Hsin Tung

Richard W. Johnson

Ching-Chang Chieng

Yuh-Ming Ferng

The INL is a

U.S. Department of Energy

National Laboratory

operated by

Battelle Energy Alliance

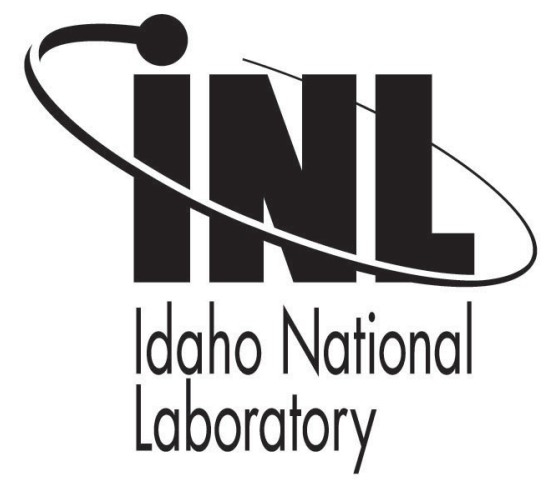

\section{November 2012}

This is a preprint of a paper intended for publication in a journal or proceedings. Since changes may be made before publication, this preprint should not be cited or reproduced without permission of the author. This document was prepared as an account of work sponsored by an agency of the United States Government. Neither the United States Government nor any agency thereof, or any of their employees, makes any warranty, expressed or implied, or assumes any legal liability or responsibility for any third party's use, or the results of such use, of any information, apparatus, product or process disclosed in this report, or represents that its use by such third party would not infringe privately owned rights. The views expressed in this paper are not necessarily those of the United States Government or the sponsoring agency. 


\section{MODELING STRATEGIES TO COMPUTE NATURAL CIRCULATION USING CFD IN A VHTR AFTER A LOFA}

\author{
Yu-Hsin Tung \\ National Tsing Hua University \\ Hsinchu,Taiwan \\ touushin@gmail.com
}

\author{
Richard W. Johnson \\ Idaho National Laboratory \\ Idaho Falls, Idaho, USA \\ Rich.Johnson@inl.gov
}

\author{
Ching-Chang Chieng \\ National Tsing Hua University \\ Hsinchu,Taiwan \\ cchieng@ess.nthu.edu.tw
}

\author{
Yuh-Ming Ferng \\ National Tsing Hua University \\ Hsinchu,Taiwan \\ ymferng@ess.nthu.edu.tw
}

\begin{abstract}
A prismatic gas-cooled very high temperature reactor (VHTR) is being developed under the next generation nuclear plant program (NGNP) of the U.S. Department of Energy, Office of Nuclear Energy. In the design of the prismatic VHTR, hexagonal shaped graphite blocks are drilled to allow insertion of fuel pins, made of compacted tristructural-isotropic (TRISO) fuel particles, and coolant channels for the helium coolant. One of the concerns for the reactor design is the effects of a loss of flow accident (LOFA) where the coolant circulators are lost for some reason, causing a loss of forced coolant flow through the core. In such an event, it is desired to know what happens to the (reduced) heat still being generated in the core and if it represents a problem for the fuel compacts, the graphite core or the reactor vessel (RV) walls. One of the mechanisms for the transport of heat out of the core is by the natural circulation of the coolant, which is still present. It is desired to know how much heat may be transported by natural circulation through the core and upwards to the top of the upper plenum.

It is beyond current capability for a computational fluid dynamics (CFD) analysis to perform a calculation on the whole $\mathrm{RV}$ with a sufficiently refined mesh to examine the full potential of natural circulation in the vessel. The present paper reports the investigation of several strategies to model the flow and heat transfer in the RV. It is found that it is necessary to employ representative geometries of the core to estimate the heat transfer. However, by taking advantage of global and local symmetries, a detailed estimate of the strength of the resulting natural circulation and the level of heat transfer to the top of the upper plenum is obtained.
\end{abstract}

\section{INTRODUCTION}

The reference design for the NGNP VHTR is nominally based on the GA Technologies [1] modular high temperature gas-cooled reactor (MHTGR). The prismatic VHTR design involves stationary graphite blocks, which have hexagonal cross sections and are drilled to accept cylindrical compacted TRISO fuel pins as well as coolant channels to conduct the helium coolant through the core. Fueled graphite blocks are stacked ten high with similarly shaped reflector blocks situated above and below the fueled blocks. The upper and lower reflector blocks are also drilled with coolant channels that coincide with those in the fueled blocks. The stacks of graphite blocks are arranged in the core such that there are three annular rings of fueled stacks with inner and outer rings of reflector graphite blocks as illustrated in Fig. 1. The core shown in Fig.1 has 66 fueled stacks, producing $350 \mathrm{MW}_{\text {th }}$. Also shown is a symmetric $1 / 12$ core section.

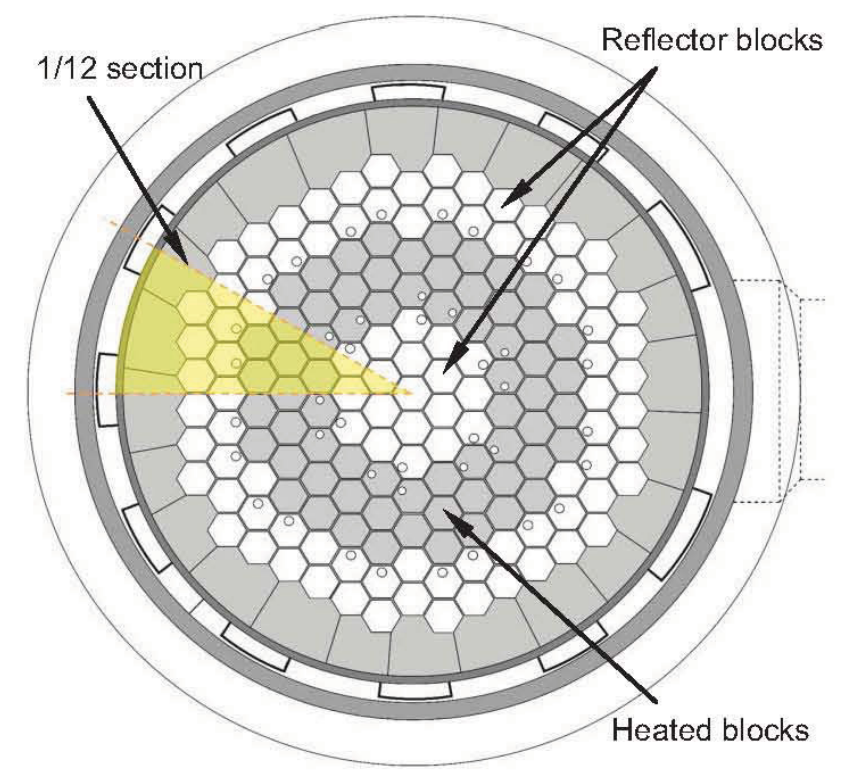

FIGURE 1. CROSS-SECTION OF VHTR PRISMATIC CORE AND SYMMETRIC 1/12 CORE SECTION. 
Figure 2 provides a schematic of the cross section of a single prismatic block. Fuel pin locations (small darker circles) and coolant channels (large lighter circles) are shown. Gaps are present between the graphite blocks because of variances in the manufacture and installation of the blocks and also from heating and irradiation during operation. These gaps allow the helium coolant to bypass the intended coolant channels drilled in the graphite blocks; the gap flow is called bypass flow. The gaps can vary in size from stack to stack and over time. It has been estimated that bypass flow can be as much as $20 \%$ of the total coolant flow in the core. Figure 2 also illustrates a onetwelfth block sector that is symmetric about each of its sides, and which is used in the present CFD study. The coolant channels and bypass flow gaps represent potential flow paths for buoyancy driven natural circulation should a loss of flow accident occur, where the forced pressure drop across the core is lost.

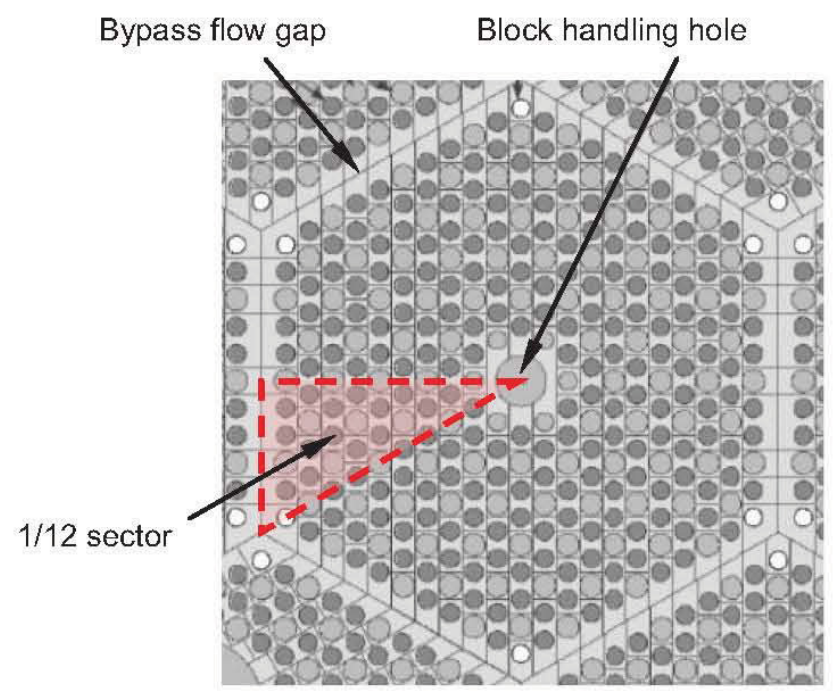

FIGURE 2. GRAPHITE BLOCK AND 1/12 BLOCK SECTOR.

A number of studies have been made of the flow and heat transfer in a prismatic VHTR during postulated accident conditions. Haque et al. [2] employ a thermal hydraulics code called THERMIX to investigate the pressurized and depressurized passive cooldown in a prismatic VHTR.

In the event that a leak or break occurs in the piping for the reactor vessel, air can ingress into the reactor lower plenum and core after an initial blowdown of helium to atmospheric levels. The air can produce severe oxidation of the graphite in the core and upper and lower plena. No et al. [3], apply the thermal hydraulics code GAMMA (gas multi-component mixture analysis), to model such an air ingress accident. GAMMA employs a porous medium model to represent the core. Oh et al. [4] also use GAMMA to compute initial conditions for air ingress into the reactor. They further employ a commercial CFD code to model flow in the reactor, where, again, a porous medium model is used to represent the core.
Several CFD studies have been made of the flow and heat transfer in a similar one-twelfth sector of a graphite block for normal operation to investigate the effects of bypass flow. Tak et al. [5] and Sato et al. [6] computed bypass flow in VHTRs with high outlet temperatures $\left(950-1000{ }^{\circ} \mathrm{C}\right)$. For lower outlet temperature VHTRs, Johnson and Sato [7] and Tung et al. [8] have collectively investigated the effects of gap width, heat generation profile, block shrinkage and surface roughness on bypass flow using CFD. An earlier study of natural circulation was made by Tung and Johnson [9] for a single one-twelfth sector and two configurations of two one-twelfth sectors in a VHTR.

The present study seeks to develop strategies to apply CFD to the VHTR core for an accident scenario where the coolant circulator is lost such that flow and heat transfer details are computed for the resulting natural circulation in the core. Such an objective is very challenging due to the significant requirement for a very large number of mesh cells and long computing times that will be incurred.

\section{CFD MODELS}

Several CFD models are employed in the present study and are based on the one-twelfth sector of a graphite column that spans the core of the prismatic VHTR. Each heated graphite column consists of an upper reflector block ( $1.189 \mathrm{~m}$ in height), 10 individual heated graphite blocks (each $0.793 \mathrm{~m}$ high) and a lower reflector block (1.585 $\mathrm{m}$ high). The one-twelfth sector includes a bypass flow gap along the short side. The CFD model further includes partial plenary regions above and below the heated column in order to provide circulation paths for natural circulation. Figure 3 shows a cross-sectional view of the onetwelfth block sector; the mesh was first developed by Sato et al. [6] and was generated using GAMBIT 2.4.6 [10]. The bypass flow gap at the left is set to $3 \mathrm{~mm}$. Similar geometries and conditions were used in an earlier study, Tung and Johnson [9]. Larger CFD models, created by adding mirror images of Fig. 3, are also investigated in the present study.

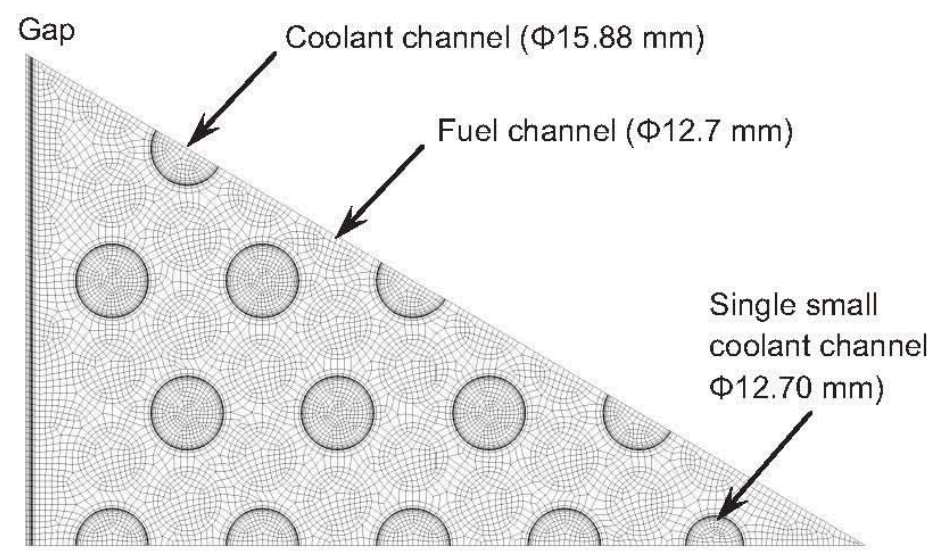

FIGURE 3. CROSS SECTIONAL VIEW OF THE CFD MODEL 
Initial conditions for the LOFA are obtained by computing flow and temperature distributions for normal operating conditions, with the upper plenum top set to a stagnation pressure inlet and the bottom of the lower plenum set to a pressure outlet. The vertical walls of the plenary regions are set to symmetry boundaries. For the initial calculation, the inlet stagnation pressure is set to $29.9 \mathrm{kPa}$ and the inlet temperature is set to $532 \mathrm{~K}\left(259^{\circ} \mathrm{C}\right)$ [1]. Graphite surfaces are assumed to be smooth. Thermal and transport properties for the helium are obtained from the National Institute of Standards and Technology (NIST) ${ }^{1}$; the properties at $6.4 \mathrm{MPa}$ are used. Graphite properties are obtained from General Atomics [11]. The fuel compact properties are those used in MacDonald et al. [12].

The heat generation profile varies axially according to a 'cosine' profile. The heat generation rate, Eqn. 1, is computed using (Johnson and Schultz [13]):

$$
q^{\prime \prime \prime}=A_{r} \times q_{\operatorname{con}}\left\{1+\left(A_{p}-1\right) \sin \left[\frac{\pi(z-1.189)}{L}\right]\right\}
$$

where $z$ is the axial coordinate, $A_{Y}$ is a radial factor, $A_{p}$ is the peak axial factor $\left(A_{p}=1.3\right), L$ is the length of the heated section $(7.93 \mathrm{~m}), 1.189$ is the depth of the upper reflector and $q_{\text {con }}$ is a constant that is set to provide the correct total heat generation. $q_{\text {con }}$ is set to $21,103,716 \mathrm{~W} / \mathrm{m}^{3}$ for the $350 \mathrm{MW}$ th MHTGR. The peak radial factor, given as $A_{r}=1.25$, is the expected maximum factor by which the heat generation rate will exceed the average generation rate $\left(A_{r}=1.0\right)$ in the lateral coordinate in the core. Figure 4 illustrates the variation of heat generation rate with core depth for average and peak radial factors. For the LOFA transient calculations, the stagnation inlet and pressure outlets are changed to no-slip walls (and, therefore, zero pressure drop across the core). Also, the heat generation rates are set to ten percent of the normal operating values. For the LOFA transient, the reference elevation is given as the top of the core where the reference density is set to $5.71 \mathrm{~kg} / \mathrm{m}^{3}(532 \mathrm{~K}, 6.4 \mathrm{MPa})$.

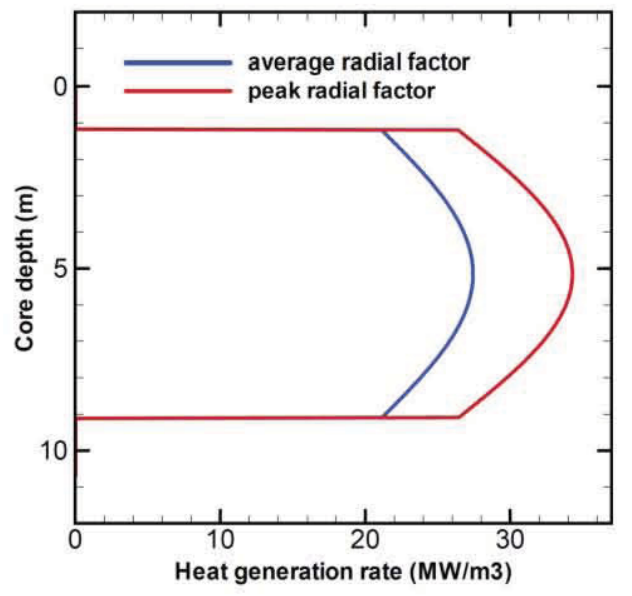

FIGURE 4. AVERAGE AND PEAK HEAT GENERATION.

\footnotetext{
${ }^{1} \mathrm{http}: / /$ webbook.nist.gov/chemistry/fluid
}

\section{BEST PRACTICES}

The commercial CFD code STARCCM+ version 6.04.016 [14] is used for all calculations. The discretization is formally second order accurate. All results reported herein for STARCCM+ are converged to about $1 \times 10^{-4}$. A grid convergence study performed for the present calculations is detailed in Table 1 . Results were obtained for normal operating conditions for four different grids of increasing fineness for a one-twelfth sector (not including the plenary sections) of 2.02 , $4.08,7.62$ and 13.6 million cells. Only the 2.02 million cell mesh is seen to be too coarse for accurate results. The differences between the other three grids are very small (lower than $0.5 \%$ ). The 4.08 million cell mesh is used for the present study. The grid for the present one-twelfth sector, including the upper and lower plena, has 7.8 million cells. Larger CFD models used herein have a multiple of that many cells depending on how many one-twelfth sectors are employed.

TABLE 1. GRID CONVERGENCE DETAILS FOR 4 GRIDS.

\begin{tabular}{|l|c|c|c|c|}
\hline \multicolumn{1}{|c|}{ Grid (million cells) } & 13.6 & 7.62 & 4.08 & 2.02 \\
\hline Total mass flow rate $(\mathrm{kg} / \mathrm{s})$ & 0.224 & 0.223 & 0.223 & 0.225 \\
\hline Gap flow fraction $(\%)$ & 4.03 & 4.04 & 4.07 & 4.06 \\
\hline Max fuel temperature $\left({ }^{\circ} \mathrm{C}\right)$ & 902 & 902 & 903 & 896 \\
\hline Max channel temp $\left({ }^{\circ} \mathrm{C}\right)$ & 792 & 790 & 794 & 786 \\
\hline Max helium temp variation $\left({ }^{\circ} \mathrm{C}\right)$ & 88 & 86 & 89 & 90 \\
\hline Bulk outlet temperature $\left({ }^{\circ} \mathrm{C}\right)$ & 733 & 734 & 736 & 726 \\
\hline
\end{tabular}

Implicit time discretization and the segregated flow option are employed for the LOFA transient calculations. The size of the time-step should be governed by the time scales of the transient phenomenon being simulated. A time step convergence study was performed to determine the maximum time step that could be used for the LOFA transient. Table 2 provides a summary of the results for three time step sizes: $0.01,0.1$ and $0.4 \mathrm{~s}$, at 10 seconds into the transient. The results are convergent (the variations within $1.5 \%$ ) when time-step size is $0.1 \mathrm{~s}$ or smaller. This study shows that the time scale for the transient after cessation of the coolant circulator is fairly large. The time-step size $0.1 \mathrm{~s}$ is used hereafter for all transient calculations.

TABLE 2. RESULTS FOR THREE TIME STEP SIZES.

\begin{tabular}{|l|c|c|c|}
\hline \multicolumn{1}{|c|}{ Time step $(\mathrm{sec})$} & 0.01 & 0.1 & 0.4 \\
\hline Max hot plane temp $\left({ }^{\circ} \mathrm{C}\right)$ & 869.9 & 869.8 & 869.5 \\
\hline Min hot plane temp $\left({ }^{\circ} \mathrm{C}\right)$ & 731.3 & 732.0 & 732.9 \\
\hline Max z-dir. Velocity $(\mathrm{m} / \mathrm{sec})$ & 0.546 & 0.553 & 0.573 \\
\hline Min z-dir. Velocity $(\mathrm{m} / \mathrm{sec})$ & -0.385 & -0.379 & -0.705 \\
\hline Avg. upper plenum temp $\left({ }^{\circ} \mathrm{C}\right)$ & 259.6 & 259.8 & 261.2 \\
\hline
\end{tabular}


Validation exercises were conducted by Tung et al. [8] that also apply to the present calculations. They compared wall shear stresses from smooth tube computations obtained from several different turbulence models with four published friction correlations. They found that the two-layer realizable $\mathrm{k} \sim \varepsilon$ turbulence model and all $\mathrm{y}^{+}$wall treatment [14] (also used herein for the initial conditions) produced results within $3 \%$ of the correlations for $\mathrm{y}^{+}$values within a range of 1 to 3 . Also, Tung et al. [8] compared results for Nusselt number with a published correlation for gas flow with variable properties with the same model and found a variation within $5 \%$. These partial validation results apply to the calculations made to obtain the initial conditions, which involve turbulent flow. However, for the natural circulation calculations, the flow is laminar $\left(\operatorname{Re}_{\max }<\right.$ 3000 ), such that no turbulence model is needed.

\section{MODELING STRATEGIES FOR CFD ANALYSIS}

The primary objective of the present study is to infer the thermal hydraulic behavior in the core through CFD modeling of as much of the core and plena as can be practically accomplished. To determine how much of the core should be included in the CFD models, several strategies are investigated. These are discussed below.

\section{The Effects of Upper and Lower Plena Heights}

If smaller upper and lower plena heights can be used in providing natural circulation pathways, fewer mesh cells can be used for these regions. Three different pairs of heights are employed for a $1 / 12$ sector model for the upper/lower plena: $0.35 \mathrm{~m} / 0.35 \mathrm{~m}, 1.0 \mathrm{~m} / 1.0 \mathrm{~m}, 3.0 \mathrm{~m} / 2.0 \mathrm{~m}$. The latter pair represents the actual heights of the upper and lower plena.

\section{The Effects of the Distribution of the Heat Generation}

This strategy is an exploratory strategy to see how the local geometry affects the natural circulation. Three model configurations are computed and compared. In addition to the single $1 / 12$ sector, two variations of doubling the one-twelfth sector model are also investigated. These are a $1 / 6$ sector $(\mathrm{p} 1+$ a1) and $2 \times 1 / 12$ sectors $(\mathrm{p} 0+\mathrm{a} 1)$ as shown in Fig. 5(a). The one-sixth sector employs the average generation rate $\left(A_{r}=1.0\right)$ in the upper half (a1) and the peak rate $\left(A_{r}=1.25\right)$ in the lower half (p1). The $2 \times 1 / 12$ sectors also operate with one sector at the average radial heat generation rate (a1) and one at the peak generation rate $(\mathrm{p} 0)$.

\section{The Effects of Distance Between Sectors}

This strategy is employed to determine how localized the natural circulation pathways are. Three configurations of $1 / 12$ sectors are compared; cf. Fig.5. The first configuration is the same as the $2 \times 1 / 12$ case in strategy 2 above $(\mathrm{p} 0+\mathrm{a} 1)$. For the second configuration another $1 / 12$ sector one block over is added to create case $3 \times 1 / 12$ with sectors $\mathrm{p} 0+\mathrm{a} 1+\mathrm{a} 2$. The third configuration adds one more sector one more block over to yield case $4 \times 1 / 12$ with sectors $\mathrm{p} 0+\mathrm{a} 1+\mathrm{a} 2+\mathrm{a} 3$. In each case, the sector on the left is the hot block $\left(A_{r}=1.25\right)$, and all others are average heat blocks $\left(A_{r}=1.0\right)$.

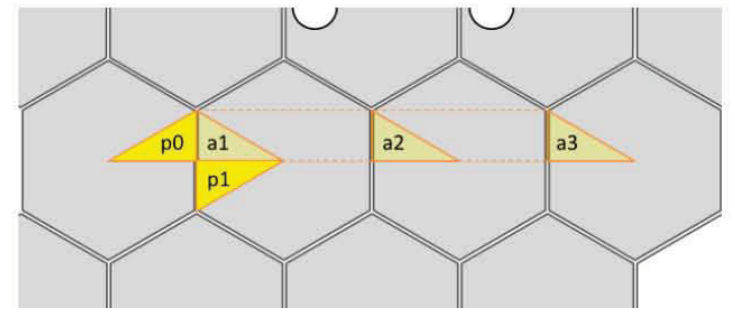

(a) Plan view

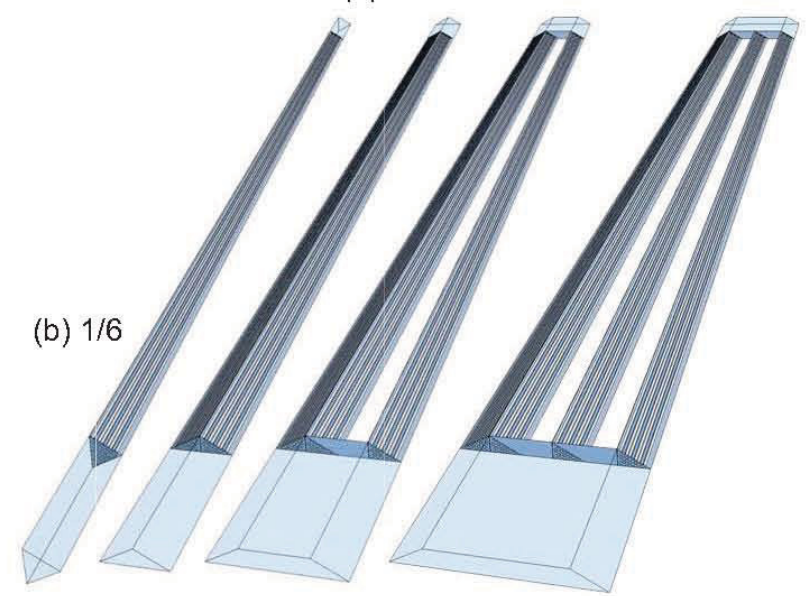

$\begin{array}{lll}\text { (c) } 2 \times 1 / 12 & \text { (d) } 3 \times 1 / 12 & \text { (e) } 4 \times 1 / 12\end{array}$

FIGURE 5. GEOMETRIES FOR STRATEGIES 2 AND 3.

\section{One-Twelfth Section of Active Core}

In the event that the previous strategies do not indicate a local effect for the natural circulation pathway, the next strategy seeks to employ the actual (lateral) geometry of the plena such that the proper pathways are used. The symmetry of the core is taken into account here. That is, for flow within the reactor vessel, there is one-twelfth symmetry of the core as indicated in Fig. 1. Further, there are symmetries within the one-twelfth section that can be exploited as the full $1 / 12$ section is probably still too large for a fine mesh CFD computation. The focus for this strategy is on the fueled stacks (grey blocks in Fig. 1) in the symmetric 1/12 section (yellow region in Fig. 1).

It is found from previous neutron transport studies, MacDonald et al. [12], that the heat generation rates are higher near the inner and outer reflectors. Hence, the sectors nearest the inner and outer reflectors are configured to have the peak heat generation rates, while the interior sectors are set to average heat generation. Figure 6(a) illustrates the one-twelfth core section with those sectors of the fueled graphite blocks set to the peak heat generation rates in red and those set to average generation rates in grey. Also shown in Fig 6(a) are two subregions, a green sub-region ( $15 \times 1 / 12$ sectors) and a blue subregion ( $9 \times 1 / 12$ sectors) that exhibit local symmetry about their interior edges. Note that the term $1 / 12$ sector still refers to a $1 / 12$ sector of an individual graphite block (Fig. 2). These subregional sections are also shown in 3D in Fig 6(b) and 6(c). 


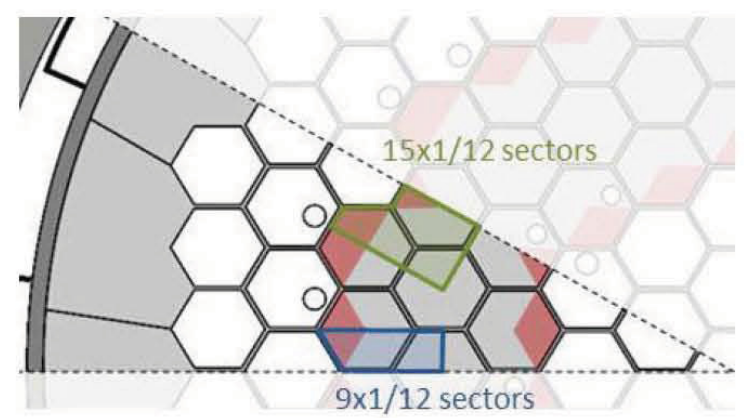

(a) Plan view

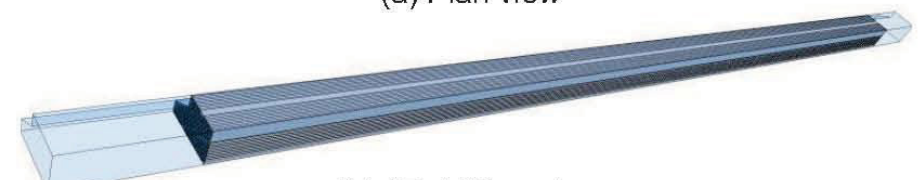

(b) $15 \times 1 / 12$ sectors

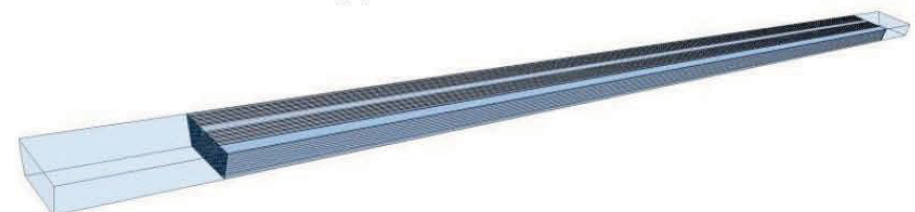

(c) $9 \times 1 / 12$ sectors

FIGURE 6. GEOMETRIES FOR STRATEGY 4.

\section{RESULTS AND DISCUSSION}

\subsection{The Effects of The Upper and Lower Plena Heights}

Results for the three upper/lower plena heights are almost the same. Table 3 summarizes key flow rates and temperatures in the core and the average helium temperature in the upper plenum at physical time $100 \mathrm{~s}$. The differences of hot plane (plane of highest fuel temperature) temperature between these three cases are very small (less than $0.5 \%$ ). Differences between the other key quantities have variations of about $1 \sim$ $2 \%$.

\section{TABLE 3. RESULTS FOR DIFFERENT HEIGHTS OF UPPER} PLENUM.

\begin{tabular}{|l|c|c|c|}
\hline Height of Upper plenum $(\mathrm{m})$ & $\mathbf{0 . 3 5}$ & 1.0 & $\mathbf{3 . 0}$ \\
\hline Max hot plane temp $\left({ }^{\circ} \mathrm{C}\right)$ & 880.2 & 880.2 & 879.9 \\
\hline Min hot plane temp $\left({ }^{\circ} \mathrm{C}\right)$ & 768.6 & 771.3 & 772.3 \\
\hline Max z-dir. Velocity $(\mathrm{m} / \mathrm{s})$ & 0.533 & 0.505 & 0.486 \\
\hline Min z-dir. Velocity $(\mathrm{m} / \mathrm{s})$ & -0.304 & -0.301 & -0.294 \\
\hline Avg. upper plenum temp $\left({ }^{\circ} \mathrm{C}\right)$ & 266.8 & 264.3 & 261.0 \\
\hline
\end{tabular}

Figure 7 plots the heat transfer through the top of the upper plenum for a period of $300 \mathrm{~s}$ for the three cases. The thermal boundary condition used for the top of the upper plenum is a constant temperature set to the initial inlet temperature of $532 \mathrm{~K}$. The heat transfer is seen to be increasing for the three cases to a kind of asymptotic level that is approximated by the dashed line. However, the dashed line is approached faster for the shorter upper plena. The reason for this is that there is more helium in the taller upper plena that is also increasing in temperature such that there is more thermal inertia for the taller heights. The heat transfer rates for heights 0.35 and $1.0 \mathrm{~m}$ are seen to be close after about $150 \mathrm{~s}$. The time for approaching the dashed line is yet longer for the $3 \mathrm{~m}$ upper plenum case. It is concluded from these results that the natural circulation is similar regardless of the upper plenum height, but that it is more efficient to use a height shorter than the full height to conserve computing time. Plenum heights of $1 \mathrm{~m} / 1 \mathrm{~m}$ are chosen for the remainder of the CFD computations.

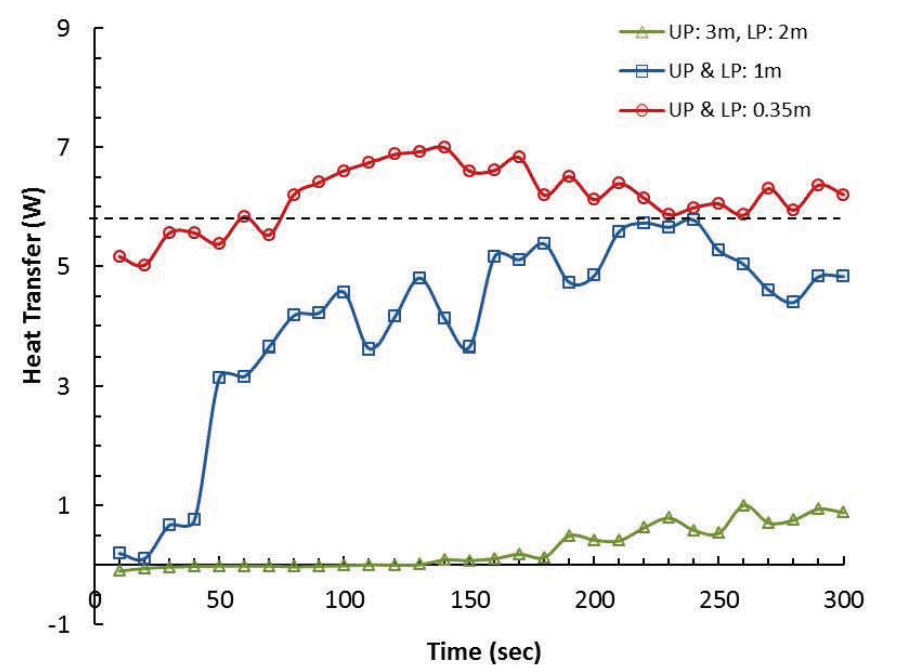

FIGURE 7. HEAT TRANSFER THROUGH TOP OF UPPER PLENUM.

\subsection{The Effects of the Distribution of Heat Generation}

Again, steady state normal operating conditions are used for the initial conditions for the three model configurations of strategy 2; LOFA transients are then computed to 100 seconds. Figure $8(\mathrm{a}-\mathrm{c})$ plots contours for the initial conditions for temperature at the hot plane and Fig. $8(\mathrm{~d}-\mathrm{f})$ shows temperature contours at the same hot plane at 100 seconds. It can be seen that the initially cooler regions, which are functions of the heat generation rate and the presence of extra bypass flow cooling, are still cooler than the hot regions at $100 \mathrm{~s}$. It is also clear that there is considerably more heat conduction from the hotter to the cooler region for the $1 / 6$ sector case than for the $2 \times 1 / 12$ sector case, diminishing the temperature difference between the two regions.

Figure 8 (g-i) shows z-velocity (vertical velocity) contours at the top of the core at $100 \mathrm{~s}$. In each configuration, natural circulation pathways are apparent, with coolant up-flow in the hotter regions and down-flow in the cooler regions. Based on the magnitudes of the vertical velocity, it is apparent that the $1 / 12$ sector produces the least amount of natural circulation as expected, the $1 / 6$ sector more and the $2 \times 1 / 12$ sector configuration the most natural circulation of the three cases. Similar computations were made by Tung and Johnson [9], but for upper/lower plenum heights of $0.35 \mathrm{~m} / 0.35 \mathrm{~m}$. 


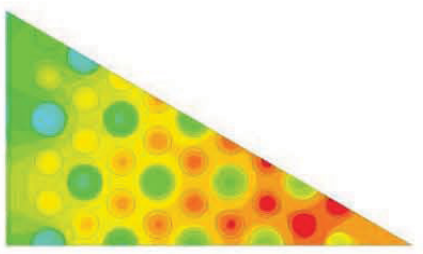

(a) $0 \mathrm{~s}, 1 / 12$ sector, temperature, $A_{r}=1.25$

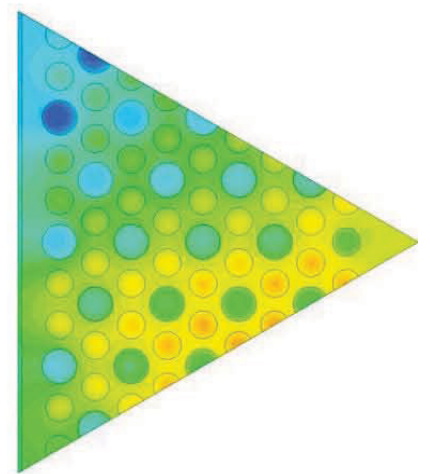

(b) $0 \mathrm{~s}, 1 / 6$ sector, temperature, $A_{r}=1.0 / 1.25$

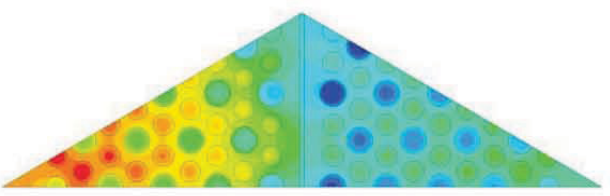

(c) $0 \mathrm{~s}, 2 \times 1 / 12$ sectors, temperature, $A_{r}=1.25 / 1.0$

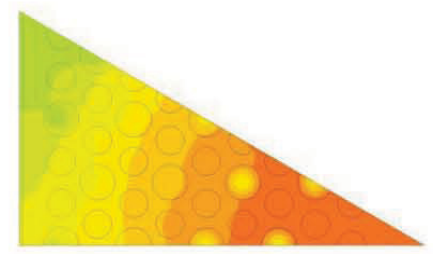

(d) $100 \mathrm{~s}$, hot plane temperature, $A_{r}=1.25$

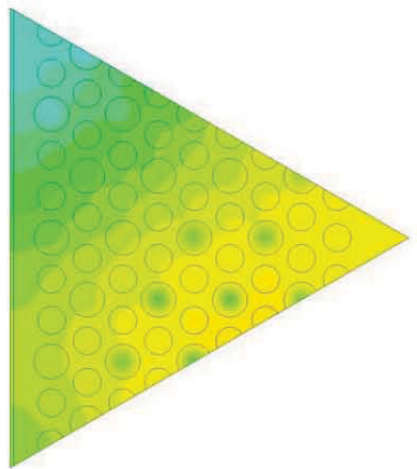

(e) $100 \mathrm{~s}, 1 / 6$ sector, temperature, $A_{r}=1.0 / 1.25$

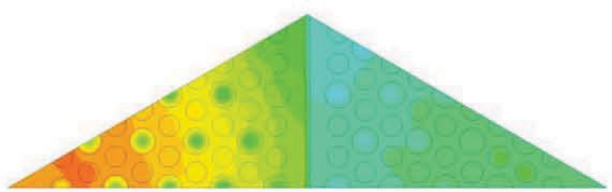

(f) $100 \mathrm{~s}, 2 \times 1 / 12$ sectors, temperature, $A_{r}=1.25 / 1.0$

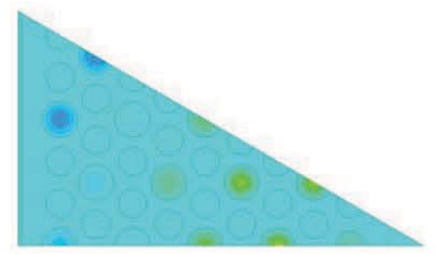

(g) $100 \mathrm{~s}, 1 / 12$ sector, z-velocity, $A_{r}=1.25$

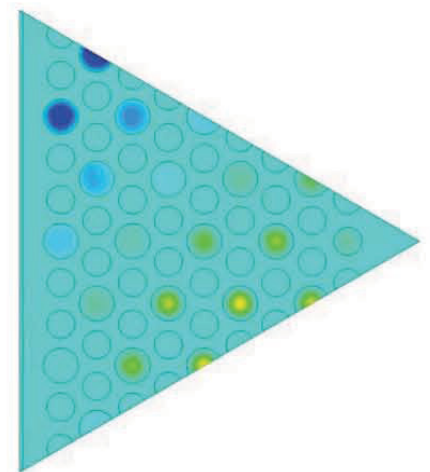

(h) $100 \mathrm{~s}, 1 / 6$ sector, z-velocity, $A_{r}=1.0 / 1.25$

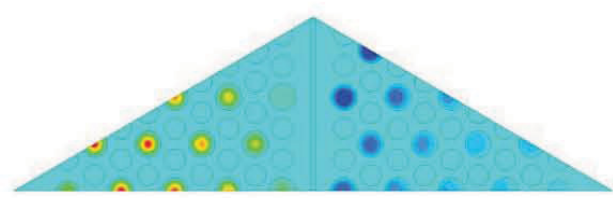

(i) $100 \mathrm{~s}, 2 \times 1 / 12$ sector, z-velocity, $A_{r}=1.25 / 1.0$
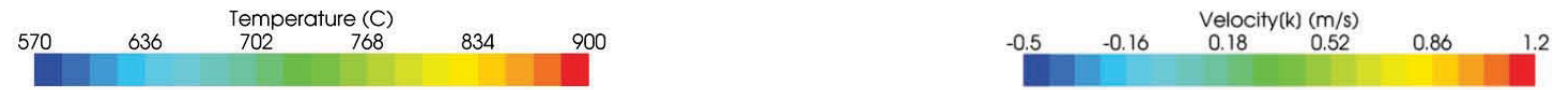

FIGURE 8. HOT PLANE TEMPERATURE CONTOURS AND Z-DIRECTION VELOCITY.

Figure 9 plots the streamlines in the upper plenum for the $1 / 12,1 / 6$ and $2 \times 1 / 12$ sector models. It is apparent that the circulation patterns in the upper plenum are a function of the separation of the hotter and cooler regions and the space available in the upper plenum.

The heat transfer rates through the top of the upper plenum are also significantly different for the three cases. Figure 10 plots the heat transfer rates for the three model configurations for the first $100 \mathrm{~s}$ of the LOFA transient. Though the surface area for the $1 / 12$ sector case is only doubled to obtain the $1 / 6$ sector and $2 \times 1 / 12$ sector cases, the latter two cases show from 4 to 10 times the heat transfer rate as for the single $1 / 12$ sector model. Furthermore, the heat transfer rate for the $2 \times 1 / 12$ sector case shows a significant increase over the $1 / 6$ sector case by factors of 1.6 to 4 over the course of the $100 \mathrm{~s}$. This result is partly because the temperature gradient in the 1/6 sector case has been reduced due to significant heat conduction between the hotter and cooler regions, thus reducing the driving force for the buoyancy-driven flow. Also, as seen in Fig. 9, the strength of the velocity of the circulating flow in the upper plenum is stronger, indicating a stronger heat transfer rate.

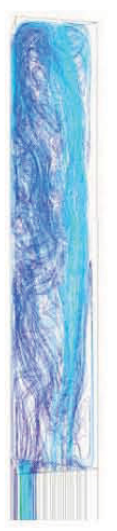

(a) $1 / 12$ sector

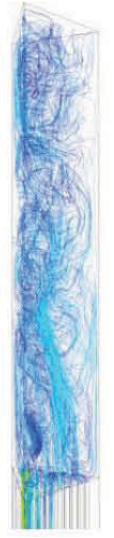

(b) $1 / 6$ sector

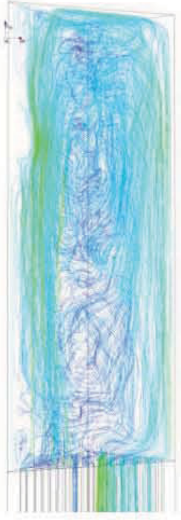

(c) $2 \times 1 / 12$ sectors

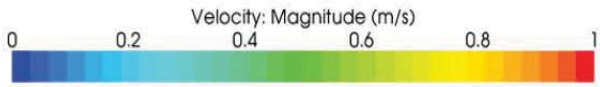

FIGURE 9. STREAMLINE PLOTS IN THE UPPER PLENUM. 


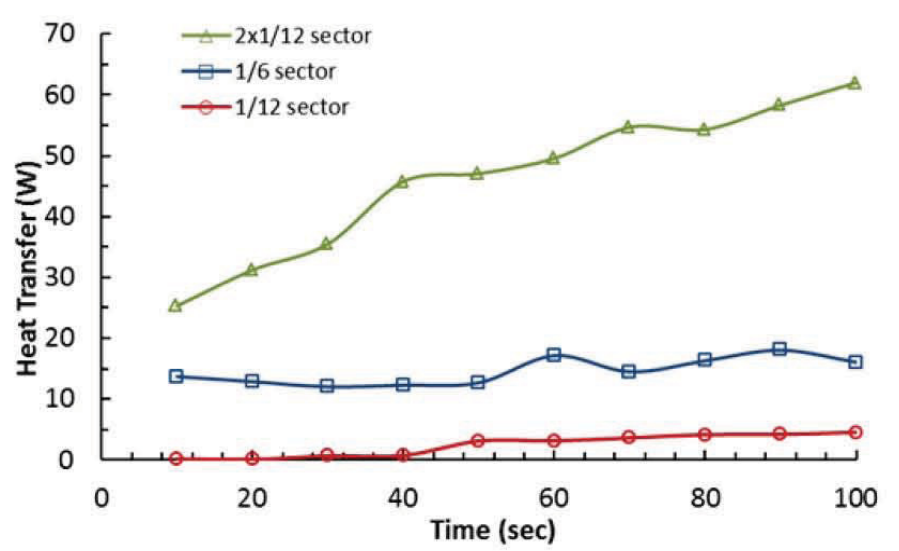

FIGURE 10. HEAT TRANSFER THROUGH TOP OF UPPER PLENUM.

\subsection{The Effect of Distance Between Sectors}

The three model configurations considered here include the 2 $\mathrm{x} 1 / 12$ sector case from the previous section as well as the $3 \mathrm{x}$ $1 / 12$ and $4 \times 1 / 12$ sector cases. Initial conditions for the hot plane temperature for the $2 \times 1 / 12$ case is given in Fig. 8(c) while Fig. 11 plots similar contours for the for $3 \times 1 / 12$ and $4 \times$ $1 / 12$ sector cases. As can be seen, there has been some heat conduction between the hot sector and the adjacent cooler sector versus the more distant sectors to the right. Figure $8(\mathrm{f})$ plots the hot plane temperature at $100 \mathrm{~s}$ while Fig. 12 plots similar contours for the second two cases. It can be seen that the more distant sectors are cooler than the one adjacent to the hot sector. Note that the temperature and velocity scales are the same for this and the previous sections.

Figure 8(i) plots the vertical velocity at $100 \mathrm{~s}$ for the $2 \times 1 / 12$ case at the top of the core; Fig. 13 plots similar velocity contours for the last two cases. Comparing these figures, it can be seen that the strongest downward (negative) velocities are for the cooler sectors farthest from the hot sector at the left. This fact is, again, due to the fact that there is no lateral heat conduction into the farthest sector as there is in the nearest one. Of course, this leads to there being a stronger potential for buoyancy-driven flow from the hot sector to the farthest cool sector.
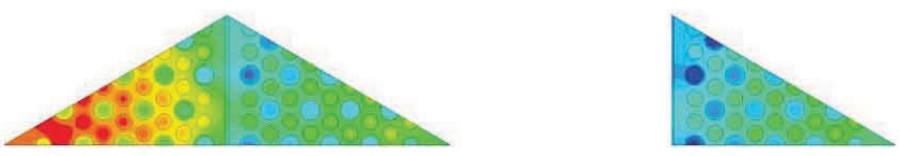

(a) $3 \times 1 / 12$ sectors

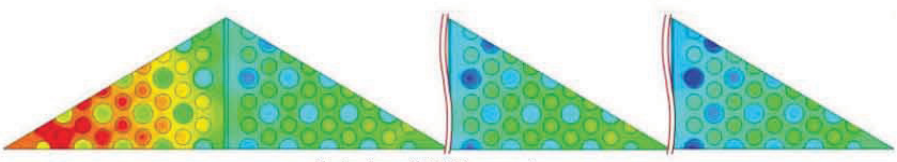

(b) $4 \times 1 / 12$ sectors

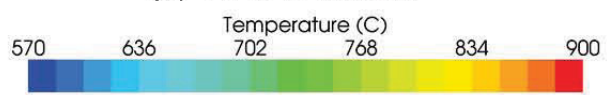

FIGURE 11. INITIAL HOT PLANE TEMPERATURE.

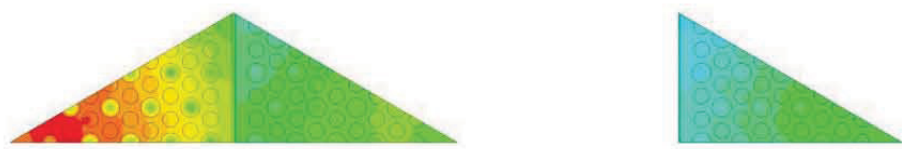

(a) $3 \times 1 / 12$ sectors

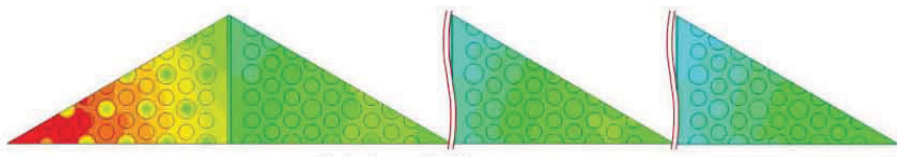

(b) $4 \times 1 / 12$ sectors

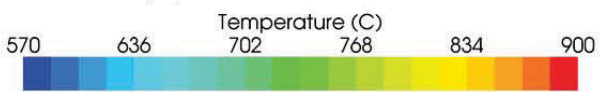

FIGURE 12. HOT PLANE TEMPERATURE AT $100 \mathrm{~S}$.

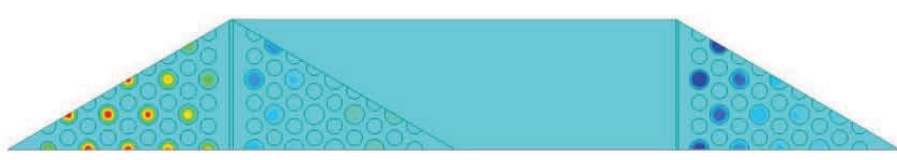

(a) $3 \times 1 / 12$ sectors

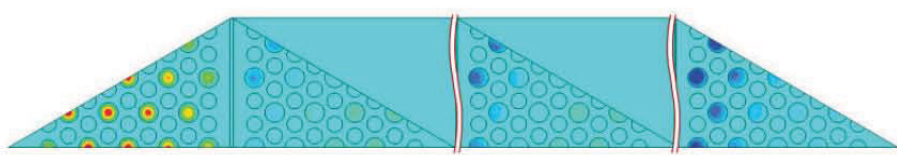

(b) $4 \times 1 / 12$ sectors

Velocity $(\mathrm{k})(\mathrm{m} / \mathrm{s})$

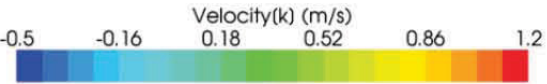

FIGURE 13. Z-DIRECTION VELOCITY AT $100 \mathrm{~S}$.

Comparing streamline plots for the three cases from Fig. 9(c) and Fig. 14, it can be seen that strong circulation patterns have developed that fully span the distance from the hot sector to the farthest cool sector. Hence, the circulation strength does not diminish with increasing distance between hot and cool sectors.

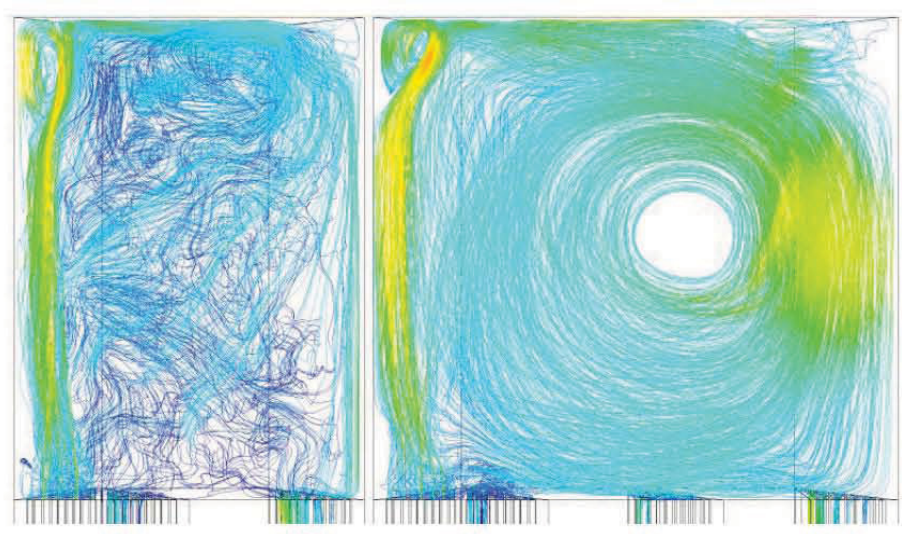

(a) $3 \times 1 / 12$ sectors

(b) $4 \times 1 / 12$ sectors

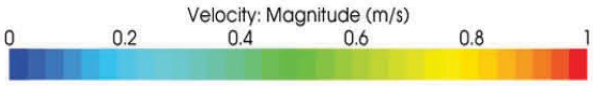

FIGURE 14. STREAMLINE PLOTS IN THE UPPER PLENUM. 
Figure 15 plots the heat transfer through the top of the upper plenum for the 2, 3 and $4 \times 1 / 12$ sector cases. The heat transfer is the highest for the case with the largest distance between hot and cool sectors (the $4 \times 1 / 12$ case), which is the same case with the strongest circulation pattern as seen in Fig. 14. This leads to the conclusion that the actual geometry of the heated core needs to be properly accounted for to obtain the correct circulation patterns and strengths.

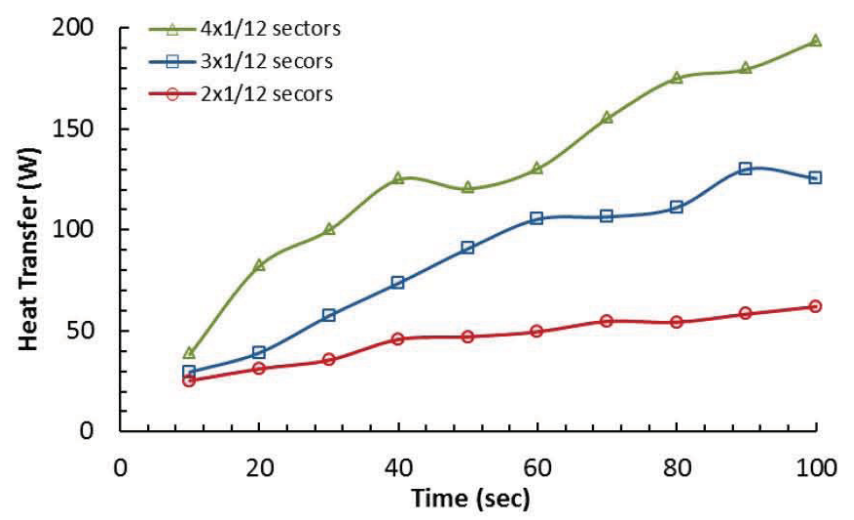

FIGURE 15. HEAT TRANSFER THROUGH TOP OF UPPER PLENUM.

\subsection{One-Twelfth Section of Active Core}

In view of the above conclusion that the actual geometry should be employed in the CFD model, the 1/12 symmetric section of the active core is considered for the CFD model. This 1/12 section contains 4 full and 3 half graphite blocks. Hence, there are $5 \frac{1}{2} \times 12=66$ block sectors of the kind that have been used in the previous sections; see Fig. 2. To build a mesh for this many sectors using the same mesh used herein would require about $66 \times 7.8-515$ million cells. While this may be possible on some supercomputers, it is not for most nuclear industry analysts. By examining the $1 / 12$ section of the core, local symmetries are apparent. Figure 6(a) illustrates two subsections within the $1 / 12$ core section that exhibit local symmetry. These two sub-sections involve 9 and 15 of the $1 / 12$ symmetric block sectors. CFD meshes for these two subsections contain 70.2 and 117 million mesh cells, respectively.

Initial conditions for these two sub-sections are obtained from steady state normal operating conditions as before. Figure 16 illustrates the temperature contours at the hot plane for these initial conditions for the two sub-sections, which have been mirror-imaged onto adjacent symmetric sub-sections as indicated in the figure, and, hence form a completed 1/12 section of the fueled core. Clearly, the coolest regions are near the bypass flow gaps. Note that the sectors adjacent to the reflector blocks are the hot sectors as indicated in Fig. 6(a).

Figure 17 plots the hot plane temperature contours at $100 \mathrm{~s}$ for the two sub-regions. The hot and cooler regions are still in the same locations as at $0 \mathrm{~s}$, though the gradients have decreased. The 9 and 15 sector models required 46,000/20,000 and $32,000 / 20,000$ iterations for steady/transient (100 s) calculations, respectively, using 768 cores in parallel.
Combined steady/transient compute times required were 14 and 17 days, respectively.

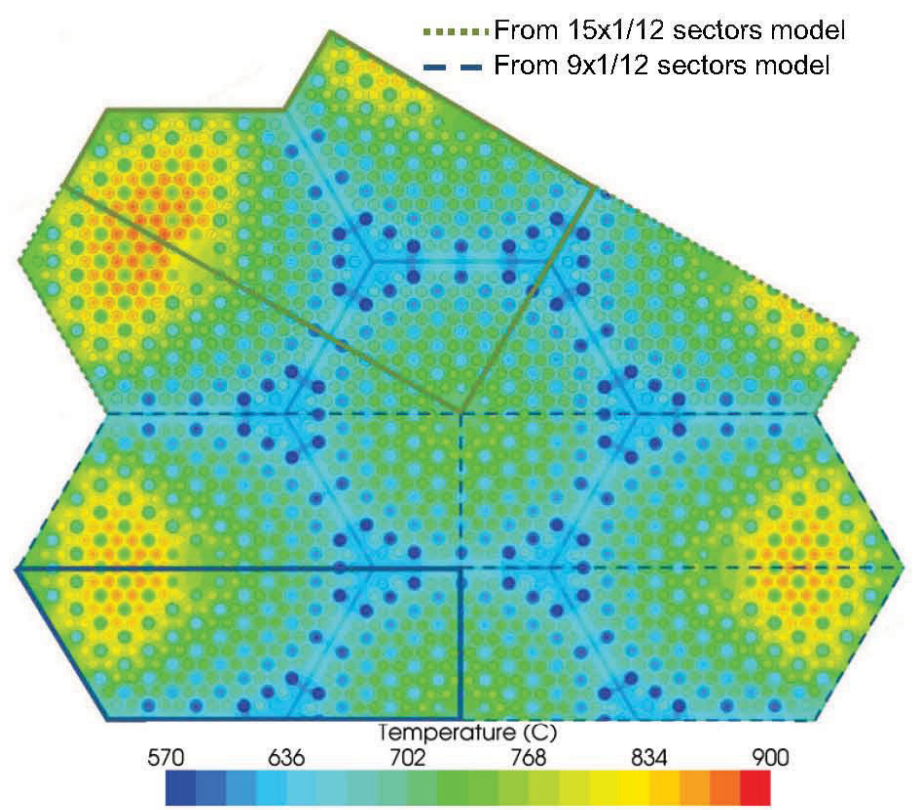

FIGURE 16. COMPOSITE INITIAL TEMPERATURES FOR THE FUELED PORTION OF 1/12 CORE SECTION.
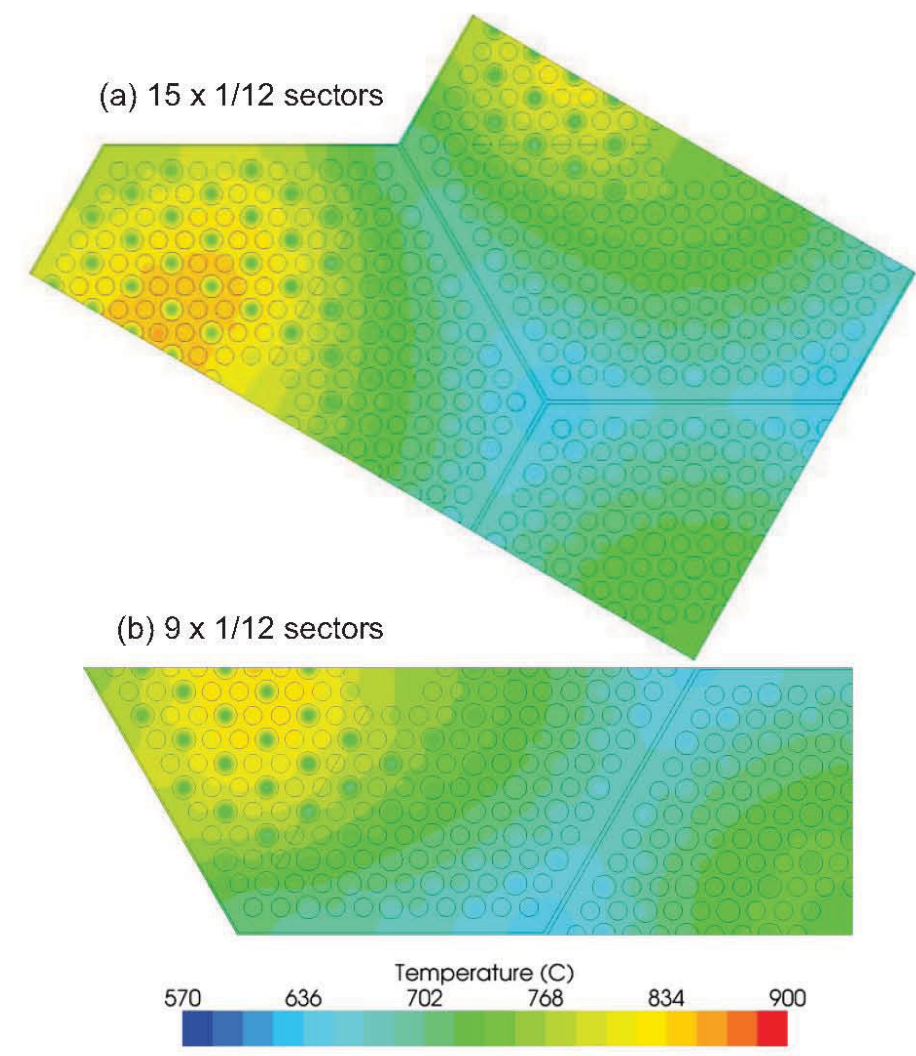

FIGURE 17. HOT PLANE TEMPERATURE CONTOURS AT $100 \mathrm{~S}$. 
Figure 18 shows contours of the vertical velocities for the two sub-regions at $100 \mathrm{~s}$. Again, the upward flow is associated with the hot sectors and downward flow is associated with the cooler sectors, and is especially strong in the regions of the bypass gaps. It is clear that the cooling provided by the bypass gaps from the initial conditions has a significant effect on the nature and strength of the natural circulation for the LOFA.

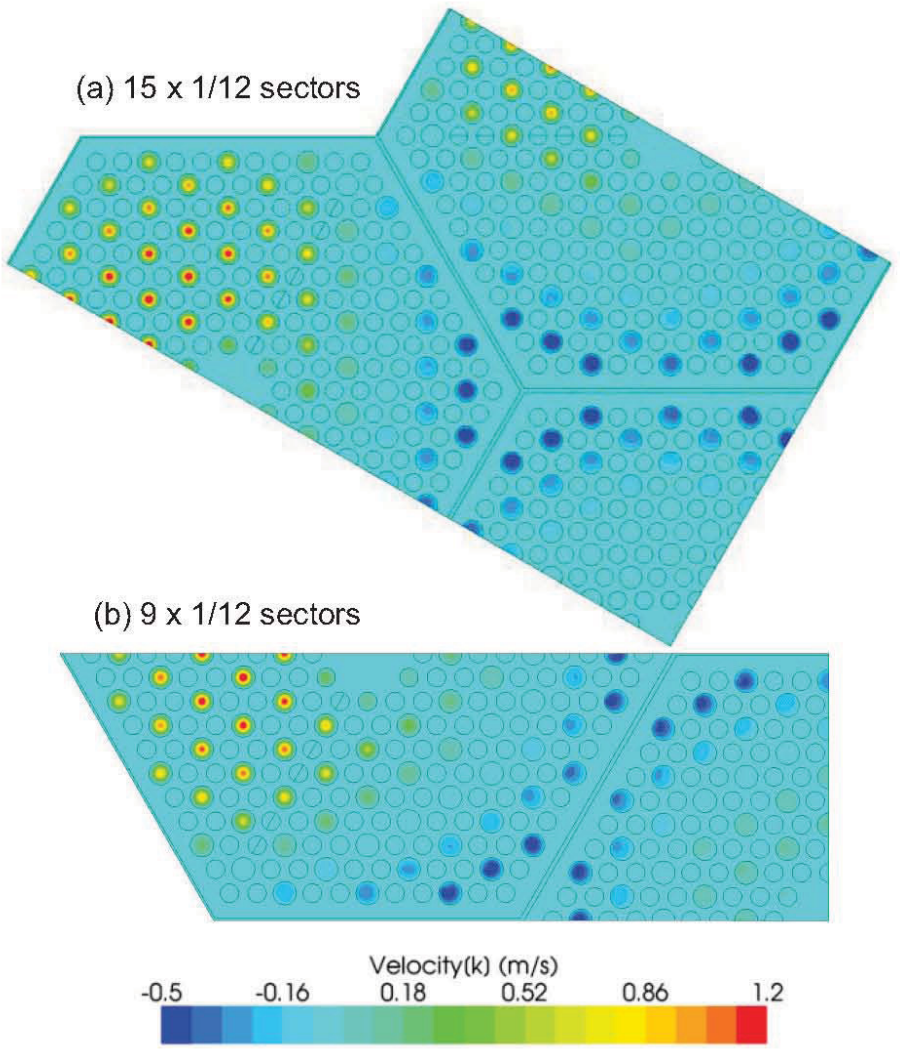

FIGURE 18. Z-DIRECTION VELOCITIES AT $100 \mathrm{~S}$.

As concluded in Sec. 5.3, it appears necessary to use the correct geometry to compute the natural circulation, which has a large affect on the size and strength of the circulation pathway. With the local symmetry present in the $1 / 12$ core section, it is likely that the flow paths generated near the inner core reflector will be similar to those generated near the outer core reflector, but in opposing directions. Hence, the geometry associated with these opposing flows should help define the natural circulation pathways. Of course, the distribution of the heat generation in the core will not be exactly the same as that used herein. However, the heat generation distribution will be a function of time and how the fuel is redistributed during refueling operations. Hence, the present calculations are only approximate but should be representative of what the natural circulation would be like. Figure 19 illustrates the flow paths for the two sub-regions at $100 \mathrm{~s}$. It can be seen that the circulation paths conform to the full lateral size of the geometry of the CFD models. However, the geometry is now representative of the actual core geometry.

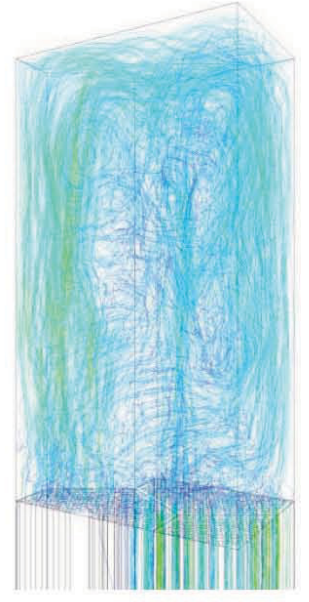

(a) $15 \times 1 / 12$ sectors

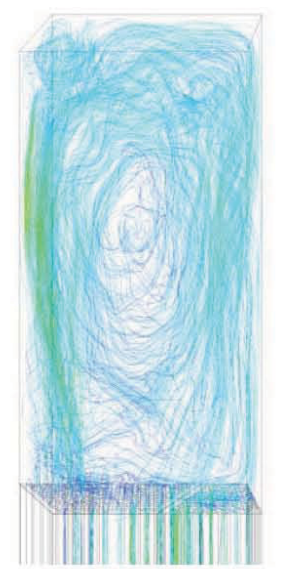

(b) $9 \times 1 / 12$ sectors

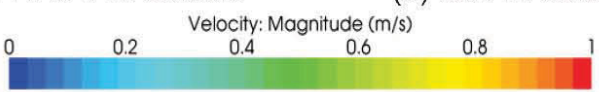

\section{FIGURE 19. STREAMLINE PLOTS IN THE UPPER PLENUM FOR THE TWO SUB-REGIONS AT $100 \mathrm{~S}$.}

Figure 20 plots the rate of heat transfer through the top of the upper plenum for the two sub-region cases. The heat transfer rate for the $15 \times 1 / 12$ sector model is about twice that for the 9 $x 1 / 12$ sectors model while the ratio of the top plane areas in these two cases is $15 / 9$ or about 1.7. The heat transfer rates are seen to be slowly increasing for the 100 seconds shown. These heat transfer rates should be good estimates of potential rates because of the appropriate geometry being used. If one multiplies the 15 sector model by two and the 9 sector model by 4 and sums, it is estimated that at $100 \mathrm{~s}$, the overall heat transfer rate to the top of the plenum for one $1 / 12$ section is about $1380 \mathrm{~W}$ or for the whole upper plenum, about $16.6 \mathrm{~kW}$.

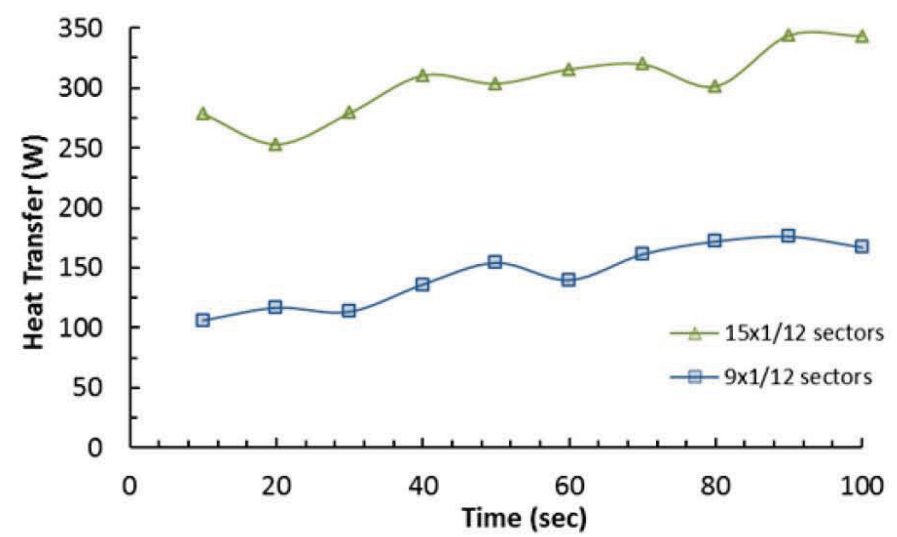

FIGURE 20. HEAT TRANSFER THROUGH THE TOP OF THE UPPER PLENUM.

Figure 21 plots the variation of maximum, average and minimum temperature in the upper plenum with time for the two sub-region cases. The temperatures for the two cases are increasing and are actually very close to each other for the three 
measures of temperature (variations are about $2 \%$ ). Based on the present assumptions of the distribution of heat generation in $1 / 12$ active core, it is concluded that the two sub-region models ( $15 \times 1 / 12$ sectors and $9 \times 1 / 12$ sectors) are representative of the flow and thermal fields for the natural circulation that occurs after a LOFA in the present VHTR.

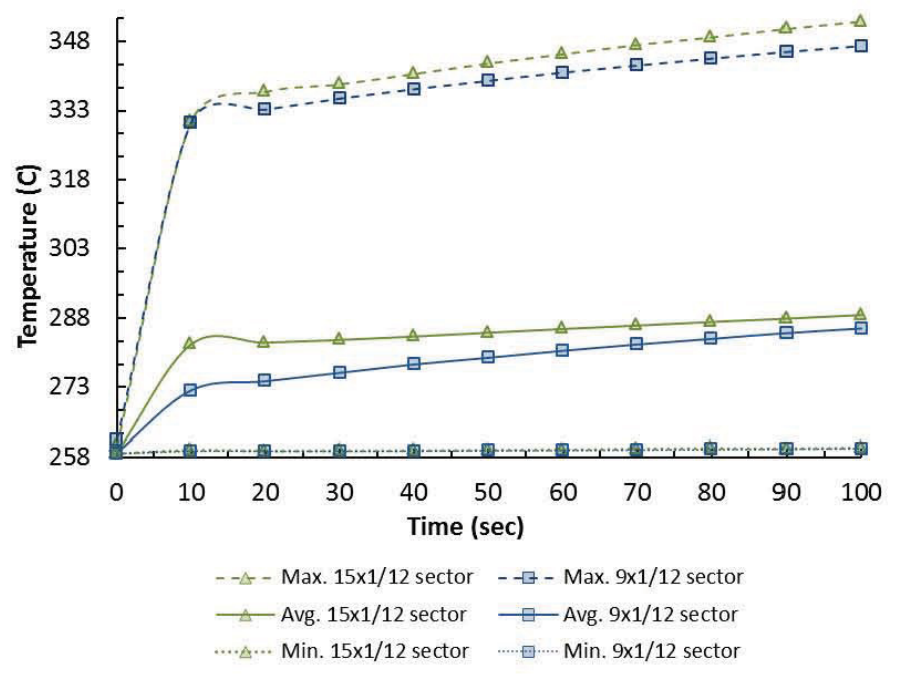

FIGURE 21. MAXIMUM, AVERAGE AND MINIMUM TEMPERATURE VARIATION IN THE UPPER PLENUM.

\section{CONCLUSIONS}

A number of computational strategies for application of CFD to the analysis of a loss of flow accident in a VHTR have been investigated. Best practices for the application of CFD were followed, including demonstration of grid and temporal convergence and partial validation. It is concluded that a shorter height for the upper and lower plena than the actual heights can be used to reduce mesh size and compute time. It was found that the distribution of heat generation for the initial steady state and transient calculations has a significant effect on the strength of natural circulation and heat transferred through the top of the upper plenum. It was also found that the separation of the included partial columns of heated core has a strong effect on the natural circulation. The latter two findings led to the conclusion that appropriate geometry for the CFD model should be used.

The symmetries present in the VHTR core led to the strategy of using two sub-regions within a one-twelfth section of the core to model natural circulation loops and the resultant heat transferred through the top of the upper plenum. These two subregions include only 15 and 9 block sectors, respectively, which are used to estimate the heat transferred for the 66 block sectors present in a one-twelfth section of the whole core. The results for the one-twelfth core section are then used to obtain a representative estimate of the heat that would be transferred to the top of the full upper plenum in the event of a LOFA; this heat transfer rate is estimated to be $16.6 \mathrm{~kW}$ at $100 \mathrm{~s}$ into the transient. It is evident that the presence of a $3 \mathrm{~mm}$ bypass flow gap between blocks has a significant effect on the temperature distribution in the blocks, which, in turn, has a significant effect on the natural circulation. Finally, it is concluded that CFD can be a powerful tool to perform detailed thermal hydraulic analysis for nuclear reactors.

\section{NOMENCLATURE}

$\begin{array}{ll}A_{p} & \text { axial factor for heat generation } \\ A_{r} & \text { radial factor for heat generation } \\ \text { CFD } & \text { computational fluid dynamics } \\ L & \text { axial length of heated core } \\ \text { LOFA } & \text { loss of fluid accident } \\ \text { MHTGR } & \text { modular high temperature gas-cooled reactor } \\ \text { NGNP } & \text { next generation nuclear power plant } \\ q \text { "” } & \text { heat generation rate } \\ q_{\text {con }} & \text { constant in heat generation equation needed to } \\ & \text { attain overall total generation rate } \\ \text { RV } & \text { reactor vessel } \\ \text { TRISO } & \text { tristructural-isotropic nuclear fuel } \\ \text { VHTR } & \text { very high temperature reactor } \\ z & \text { axial (vertical) coordinate }\end{array}$

\section{ACKNOWLEDGMENTS}

The authors thank the National Center for High-Performance Computing, Taiwan for computing resources and the National Science Council, Taiwan for financial support under Grant NSC 100-2623-E-007-003-NU.

\section{REFERENCES}

[1] GA Technologies, Inc., 1992, "Preliminary Safety Information Document for the Standard MHTGR," doc. HTGR86-024 rv. 13.

[2] Haque, H., W. Feltes and G. Brinkman, 2006, "Thermal Response of a Modular High Temperature Reactor During Passive Cooldown Under Pressurized and Depressurized Conditions," Nucl. Eng. Des., 236, pp. 475-484.

[3] No, H. C., H. S. Lim, J. Kim, C. Oh, L. Siefken and C. Davis, 2007, "Multi-Component Diffusion Analysis and Assessment of GAMMA Code and Improved RELAP5 code," Nucl. Eng. Des., 237, pp. 997-1008.

[4] Oh, C. H., H. S. Kang and E. S. Kim, 2011, "Air-Ingress Analysis: Part 2-Computational Fluid Dynamics Models," Nucl. Eng. Des., 241, pp. 213-225.

[5] Tak, N., M-H Kim, W. Lee, 2008, "Numerical investigation of heat transfer within the prismatic fuel assembly of a very high temperature reactor," Annals of Nuclear Energy, 35 , pp. 1892-1899.

[6] Sato, H., R. W. Johnson, R. R. and Schultz, 2010, "Computational Fluid Dynamic Analysis of Core By-pass Flow Phenomena in a Prismatic VHTR, Annals of Nuclear Energy," 37, pp. 1172-1185.

[7] Johnson, R. W., and H. Sato, 2010, "Bypass Flow Computations using a One-Twelfth Symmetric Sector for Normal Operation in a 350 MWth Prismatic VHTR," HTR2010 Conference paper 152 . 
[8] Tung, Y-H, R. W. Johnson and H. Sato, 2011, "Effects of Graphite Surface Roughness on Bypass Flow Computations for an HTGR," ASME paper PVP2011-58053.

[9] Tung, Y-H., and R. W. Johnson, 2011, "CFD Calculations of Natural Circulation in a High Temperature Gas Reactor Following Pressurized Circulator Shutdown," ASME paper IMECE2011-64259.

[10] ANSYS, Inc., 275 Technology Drive, Canonsburg, PA 15317.

[11] General Atomics, 1977, "Safety Analysis Report use of H451 Graphite in Fort St. Vrain Fuel Elements," GLP-5588.

[12] MacDonald, P., J. Sterbentz, R. Sant, P. Bayless, R. Schultz, H. Gougar, R. Moore, A. Ougouag, W. Terry, 2003, "NGNP Preliminary Point Design Results of the Initial Neutronics and Thermal-Hydraulic Assessments," INEEL/EXT03-00870.

[13] Johnson, R. W. and Schultz, R. R., 2004, "Bounding Estimate for the 'Hot' Channel Coolant Temperature and Preliminary Calculation of Mixing in the Lower Plenum for the NGNP Point Design Using CFD," Report INEEL/EXT-0402570, Rev. 1, Idaho National Engineering \& Environmental Laboratory.

[14] STAR-CCM+, version 6.04.016, 2011, CD-adapco, 60 Broadhollow Road, Melville, NY 11747. 